\title{
Model Analysis of Smoke Control in Long Tunnel: Findings from Hsueh-Shan Tunnel Accident in Taiwan
}

\author{
Yi-Hong Chang ${ }^{1}$, Chen-Wei Chiu ${ }^{2}$ and Chi-Min Shu ${ }^{1}$ \\ 1. Department of Safety, Health, and Environmental Engineering, National Yunlin University of Science and Technology, Douliou, \\ Yunlin 64002, Taiwan, R.O.C.
}

2. Department of Fire Safety, National Taiwan Police College, Taipei 64002, Taiwan, R.O.C.

\begin{abstract}
The common properties of risk in long tunnel fires are high temperature, extreme difficulty of evacuation, rescue urgency and obstacle to rescue operation. Therefore, a complete ventilation design is an indispensable safety measure. Hsueh-Shan Tunnel is the longest in Taiwan, the fifth longest in the world. On May 7, 2012, a serious tunnel fire caused two deaths and numerous victims suffered from smoke inhalation injury. Apart from this, there was smoking entering the cross-passages and shafts which were important for evacuation. In this research, the current ventilation system in Hsueh-Shan Tunnel was simulated with FDS (fire dynamics simulator) software, and the statistics of smoke, visibility and temperature profile were analyzed. The results of this research showed that, with the current ventilation system, the time was shorter and the distance was longer for the smoke spreading windward than in other models. Furthermore, the visibility of windward victims was more affected and the temperature above the fire source was higher than those in other systems. When the wind speed in tunnel is within $2.0 \sim 4.0 \mathrm{~m} / \mathrm{s}$, the condition for turning off the ventilation fan within $250 \mathrm{~m}$ upwind from the fire source can be prominently reduced to $50 \mathrm{~m}$ upwind from the fire source. This not only could avoid plume disturbance but also could be maintained. If victims' evacuation should be given the highest priority, it is recommended to straightly activate the maximum power of the fan.
\end{abstract}

Key words: Long tunnel fires, ventilation system, visibility, plume disturbance, victims' evacuation.

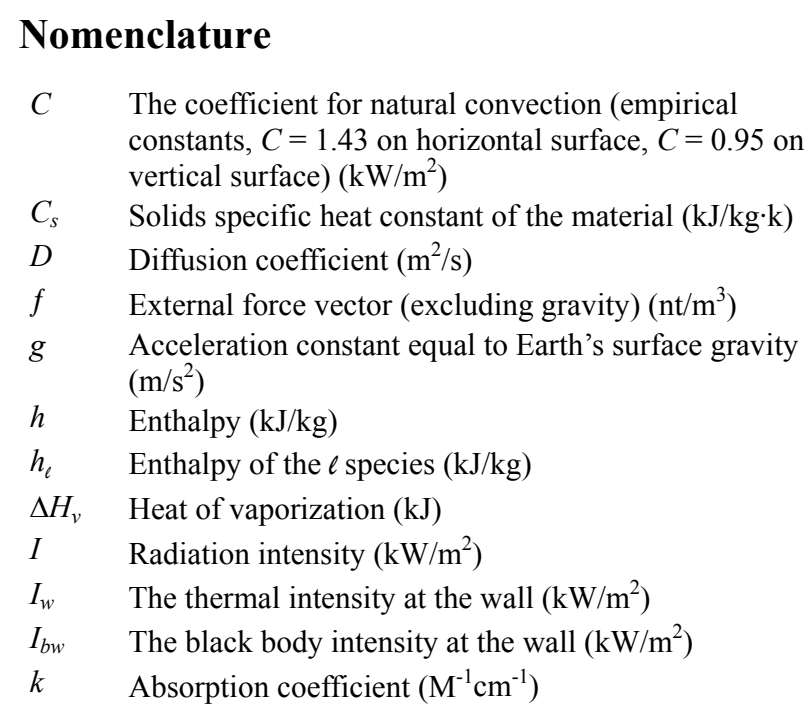

Corresponding author: Chi-Min Shu, Ph.D., professor, research fields: process safety, runaway reaction, design of emergency relief system, fire and explosion prevention, chemical emergency response technique, explosion criticality and flammability studies for reactive materials, Li-ion cell thermal hazard and abuses, thermal hazard evaluation for organic peroxides and quantitative risk assessment.
$K \quad$ Thermal conductivity; suppression decay factor (kW/mk)

$k_{s} \quad$ Solids conductivity of the material $(\mathrm{kW} / \mathrm{mk})$

$L \quad$ A characteristic distance related to the size of the plate (m)

$m^{\prime \prime} \quad$ The mass loss rate of fuel $(\mathrm{kg} / \mathrm{s})$

$p_{r} \quad$ Prandtl number $\left(p_{r}=0.7 \sim 0.8\right.$ of air and gas $)$

$p \quad$ Pressure $\left(\mathrm{nt} / \mathrm{m}^{2}\right)$

$\dot{q}^{\prime \prime} \quad$ Heat release rate per unit volume $\left(\mathrm{kW} / \mathrm{m}^{3}\right)$

$q^{\prime \prime} \quad$ Convective flux to a solid surface $\left(\mathrm{kW} / \mathrm{m}^{2}\right)$

$\dot{q}_{c}^{\prime \prime} \quad$ Convective heat fluxes at the surface $\left(\mathrm{kW} / \mathrm{m}^{3}\right)$

$q_{p}^{\prime \prime} \quad$ The energy available for paralyzing fuel $\left(\mathrm{kW} / \mathrm{m}^{3}\right)$

$q_{r}^{\prime \prime} \quad$ Radiative heat fluxes at the surface $\left(\mathrm{kW} / \mathrm{m}^{3}\right)$

$S \quad$ Unit vector in direction of radiation intensity (m)

$T \quad$ Air temperature $\left({ }^{\circ} \mathrm{C}\right)$

$T_{s} \quad$ Temperature of the material $\left({ }^{\circ} \mathrm{C}\right)$

$t \quad$ Time (s)

$U \quad$ Dynamic viscosity $(\mathrm{m} / \mathrm{s})$

$V \quad$ Volume of the enclosure $\left(\mathrm{m}^{3}\right)$

$\dot{W}_{\ell}^{\prime \prime \prime} \quad$ Volume fraction of species $\ell\left(\mathrm{m}^{3}\right)$

$x \quad$ Specific heat $(\mathrm{kJ} / \mathrm{kg})$

$Y_{\ell} \quad$ Mass fraction of species $\ell(\mathrm{kg})$ 
$\delta \quad$ Solids thickness of the material (m)

$\varepsilon \quad$ Emissivity rate (w/s)

$\rho \quad$ Density $\left(\mathrm{kg} / \mathrm{m}^{3}\right)$

$\lambda \quad$ Wavelength $(\mu \mathrm{m})$

$\rho_{S} \quad$ Solids density of the material $\left(\mathrm{kg} / \mathrm{m}^{3}\right)$

$\sigma \quad$ Stefan-Boltzman constant $\left(\mathrm{W} \cdot \mathrm{m}^{-2} \mathrm{~K}^{-4}\right)$

$\Omega \quad$ Absolute humidity $\left(\mathrm{g} / \mathrm{m}^{3}\right)$

\section{Introduction}

With the improvement of living standard and development of transportation industry, a variety of tunnels have shown up and fire safety appears as quite an important topic. Road tunnels, with its closed and restricted space, could hardly perform smoke exhaust naturally. Thus the smoke and heat would fill the tunnel without escape, causing high temperature, extreme difficulty in evacuation, rescue operation and smoke spreading. The smoke in a tunnel fire might cause low visibility and casualties due to carbon monoxide inhalation or poisoning. Apart from above-mentioned, the evolved heat from fire would lead to collapse of tunnel structure and damage of equipment, any possible casualties may ensue. Therefore, a complete ventilation design was an indispensable safety measure precaution in long tunnel.

This research adopted smoke control modes of actual operation to analysis the hazard of high fire situation while fire occurred on beginning, middle and final stage in emergency control center of Hsueh-Shan Tunnel. At the present stage, while fire occurred in Hsueh-Shan Tunnel, an existing smoke control strategy has been mainly conducted, which is divided into "evacuation mode" and "exhaust smoke mode", and "a single hole way" and "two holes-single way", etc. The actual modes of operation are divided into 28 kinds of evacuation mode and 12 kinds of exhaust smoke modes. This study adopted a single hole way with the original four kinds of evacuation mode and six kinds of exhaust smoke mode as a smoke control optimum design study direction.

This study employed the CFD (computation fluid dynamics) based FDS (fire dynamics simulator) [1] software, which developed by the U.S. NIST (National Institute of Standards and Technology), to simulate the fire accident smoke exhaust device at the exact time when accident occurs. The FDS is nowadays widely adopted by researchers for tunnel fire scenarios [2-7], which was used to verify tunnel fire in full-scaled and down-sized model. In practice, the results showed consistency in the temperature of jet stream, length of countercurrent smoke layer and critical wind speed with experimental results. Lee [5] and Lotschberg [8] focused on simulating long tunnel fire, while Lin [9] and Kirytopoulos et al. [10] intended to discuss the environment for evacuation in tunnel fire.

Hsueh-Shan Tunnel is currently Taiwan's longest tunnel, the fifth tunnel in the Asia and the eighth longest highest tunnel. This tunnel is one-way, twin bore and it is approximately $12.9 \mathrm{~km}$ long. This research employs the Hsueh-Shan Tunnel as its study subject. Existing researches in tunnel fire simulation are mainly based on uniform speed of exhaust fans or consistent wind speed at the entrances of the tunnel [10]. However, in actual fire scene, exhaust fans on the top of the tunnel will be activated if there is no sufficient ventilation inside the tunnel to ensure certain wind speed. Therefore, in this research, the fans on top of the tunnel were used to stabilize the flow field. Moreover, by analyzing existing evacuation mode and smoke exhaust mode, the results were elucidated in the discussion of fire evacuation environment.

\section{Hsueh-Shan Tunnel Fire Accident}

The catastrophic tunnel fires since 1999 and a series of fire in some long tunnels in the summer of 2001 triggered extensive discussions and proposals related to tunnel safety in Taiwan $[11,12]$. When a fire occurs in a tunnel and in absence of sufficient air supply, large quantities of smoke are generated, filling the vehicles and any space available around them. Unless a strong flow is created and maintained, hot gases and smoke migrate in all directions. Since last two decades, there have been cases of serious long tunnel disasters, such 
as Mont Blanc Tunnel in Alps (11.6-km), transport truck fire causing 39 deaths on March 4, 1999 and Tauern Tunnel in Austria (6.4-km), fire caused by collision of truck on May 29, 1999 leading to 13 deaths. Table 1 lists the analysis of the selected fire accidents in road tunnels around the world [13].

It is constructed with one pilot tunnel and two main tunnels for eastbound and westbound traffics. The total length is $12.94 \mathrm{~km}(8.04 \mathrm{mi})$ making the Hsueh-Shan Tunnel the second longest road tunnel in East Asia and the fifth longest road tunnel in the world, as shown in Fig. 1. For this study, an actual example of a fire that occurred in Hsueh-Shan Tunnel was used and elucidated to a deeper extent.

On May 7, 2012, the most severe car accident occurred in Hsueh-Shan Tunnel ever since its establishment on June 16, 2006. A car in $26.0 \mathrm{~km}$ south slammed on the brake when its tire blew out, vehicles at the back, including a Kamalan's bus, dodged aside. However, a van and a Capital's bus crashed into the Kamalan's bus, causing fire on the van, which spread to the Capital's bus soon. The tunnel immediately filled with smoke and high temperature. This accident caused two deaths, seven major and 15 minor injuries [14]. The victims described the tunnel as fallen chimney that there are hundreds of victims who evacuated were all covered with a layer of soot. According to Taiwan Area National Freeway Bureau, Ministry of Transportation and Communications, the temperature of the tunnel on fire was $54{ }^{\circ} \mathrm{C}$ as compared with $30^{\circ} \mathrm{C}$ in average.

\section{Introduction to Simulation Software}

FDS version 5.0 is a CFD model developed by NIST to simulate the fire growth for low-speed Mach number. The program is approximated the Navier-Stokes equations [15] by discretization to the finite difference equations. The computation is treated as a DNS (direct numerical simulation) or LES (large eddy simulation). For DNS model, the dissipative terms are computed directly; For LES model, the large-scale eddies are computed whereas directly and the sub-grid scale dissipative processes are modeled. The selection of DNS or LES depends on the objective of calculation and the required resolution of computational grid. Although it is possible to compute directly the heat and mass transfers when performing a DNS, heat and mass transfers to and from solid surfaces is usually handled with empirical correlations, and turbulence is treated by means of the Smagorinsky form [16] of LES. Therefore, this study adopted LES, the default mode of operation.

\subsection{Conservation Equations}

Followings are the conservation of mass, momentum, species and energy equations for the multi-component mixture of the idea gases [17]:

- conservation of mass:

$$
\frac{\partial \rho}{\partial t}+\nabla \cdot \rho u=0
$$

- conservation of momentum:

$$
\rho\left(\frac{\partial u}{\partial t}+(u \cdot \nabla) u\right)+\nabla p=\rho g+f+\nabla \tau
$$

- energy equation:

$$
\begin{gathered}
\frac{\partial}{\partial t}(\rho h)+\nabla \cdot \rho h u-\frac{D P}{D t}= \\
Q-\nabla \cdot q^{\prime \prime}+\nabla k \nabla T+\nabla \cdot \sum_{\ell} h_{\ell}(\rho D)_{\ell} \nabla Y_{\ell} \\
\text { - conservation of species: } \\
\frac{\partial}{\partial t}\left(\rho Y_{\ell}\right)+\nabla \cdot \rho Y_{\ell} u=\nabla \cdot(\rho D)_{\ell} \nabla Y_{\ell}+\dot{W}_{\ell}^{\prime \prime \prime}
\end{gathered}
$$

\subsection{Thermal Radiation Model}

The FDS radiation model for the non-scattering gas is governed by Ref. [18]:

$$
\begin{gathered}
s \cdot \nabla I_{n}(x, s)=k_{n}(x)\left[I_{b, n}(x)-I(x, s)\right] \\
n=1,2, \ldots, N
\end{gathered}
$$

where:

$$
\begin{aligned}
& I_{b, n}=F_{n}\left(\lambda_{\min }, \lambda_{\max }\right) \sigma T^{A} / \pi \\
& I \cdot(x, s)=\sum_{n=1}^{N} I_{n}(x, s)
\end{aligned}
$$

where, $I_{n}(x, s)$ is the radiation intensity at wave length $n, I_{b, n}(x)$ is the source term given by the Planck 


\begin{tabular}{|c|c|c|c|c|c|c|c|c|c|c|c|c|c|c|}
\hline & 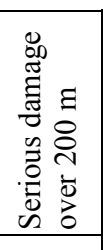 & & 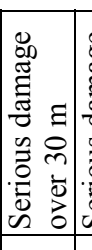 & 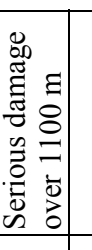 & 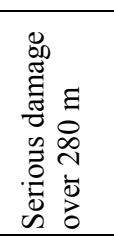 & 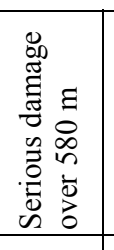 & & 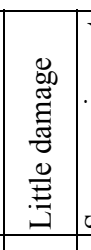 & & 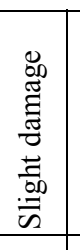 & 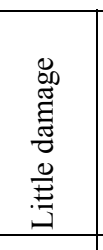 & 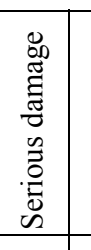 & 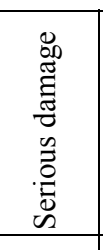 & 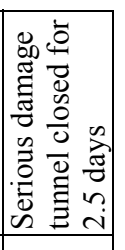 \\
\hline & 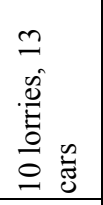 & & & 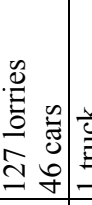 & $\frac{n}{20}$ & & & $\begin{array}{l}0 \\
0 \\
0 \\
0 \\
0\end{array}$ & & 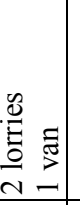 & 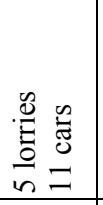 & 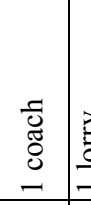 & 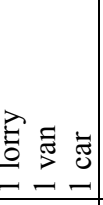 & 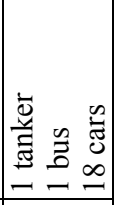 \\
\hline & & $\mid$ & 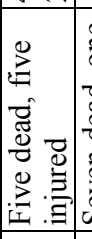 & & 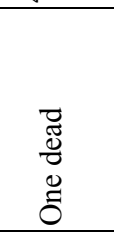 & 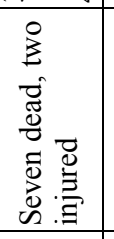 & 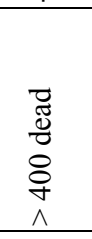 & 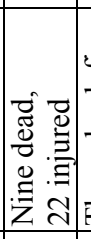 & & 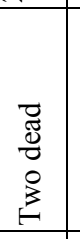 & 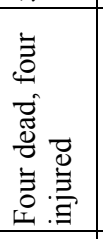 & & 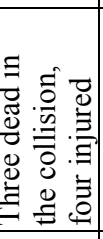 & 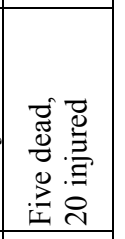 \\
\hline 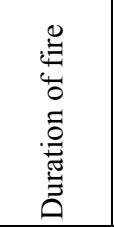 & 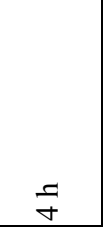 & $\begin{array}{l}\text { 音 } \\
\underline{\underline{n}} \\
\end{array}$ & & 흠 & & 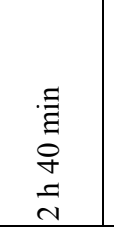 & & & & $\frac{\vec{N}}{\mathrm{~N}}$ & 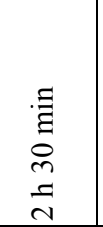 & $\Xi$ & $\equiv$ & \\
\hline 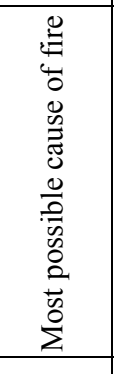 & 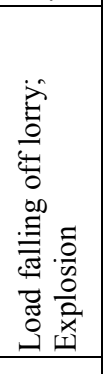 & \begin{tabular}{|c|} 
\\
$\dot{0}$ \\
\end{tabular} & 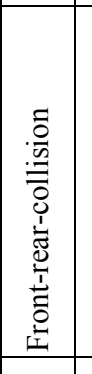 & 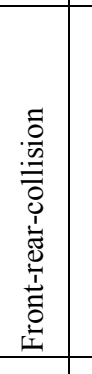 & 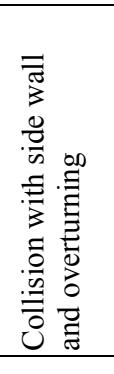 & 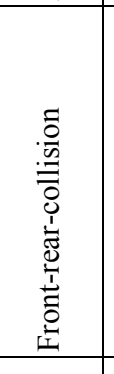 & 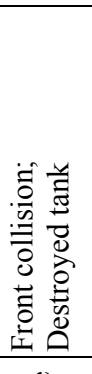 & 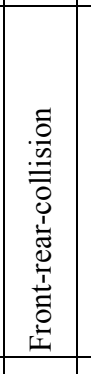 & 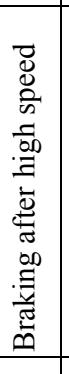 & 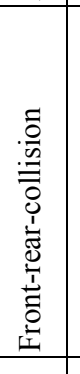 & 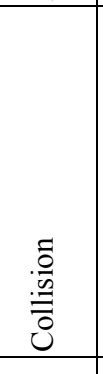 & 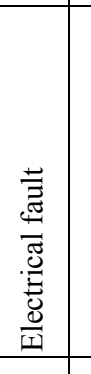 & 童 & 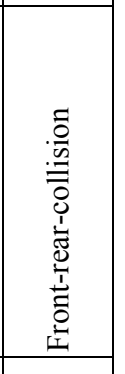 \\
\hline 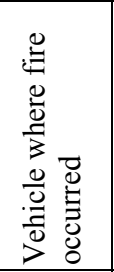 & 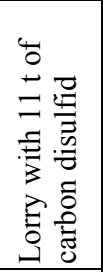 & 咅 & 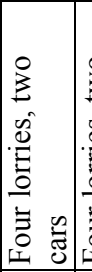 & 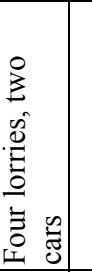 & 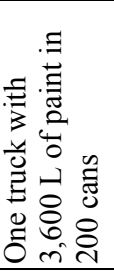 & 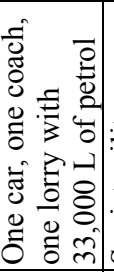 & 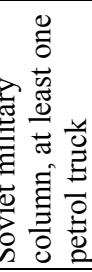 & 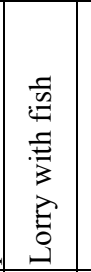 & 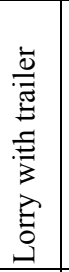 & . & 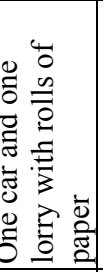 & 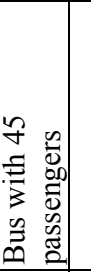 & 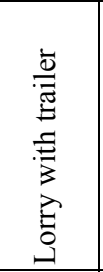 & 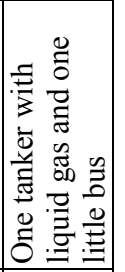 \\
\hline 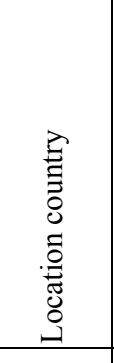 & 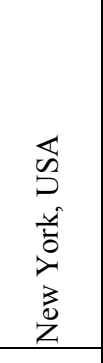 & 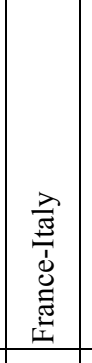 & 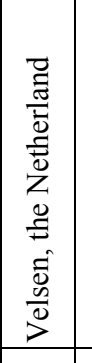 & 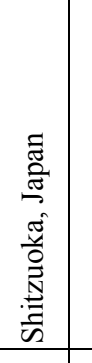 & 离 & 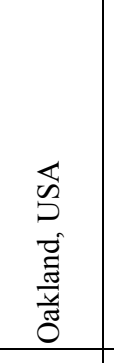 & 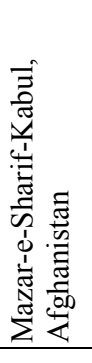 & 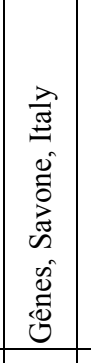 & 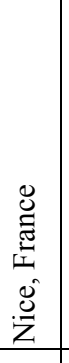 & 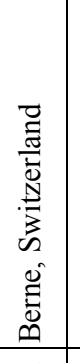 & 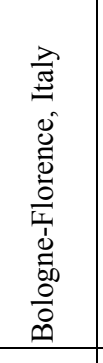 & 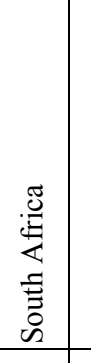 & 喽 & 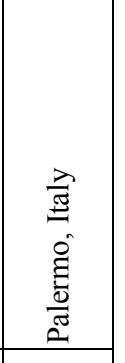 \\
\hline 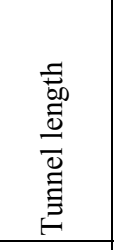 & 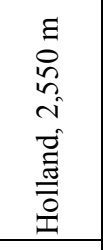 & 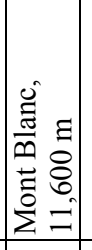 & 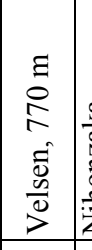 & 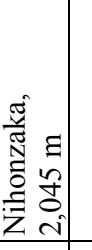 & 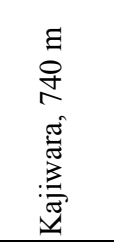 & 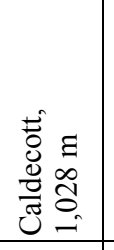 & 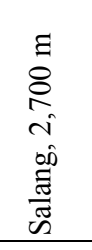 & 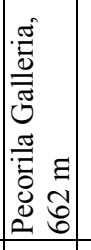 & 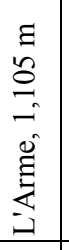 & 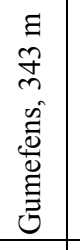 & 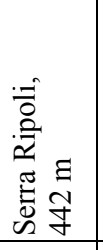 & 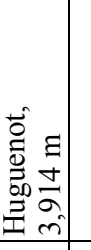 & 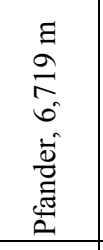 & 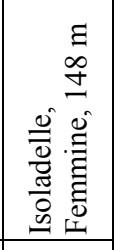 \\
\hline 吢 & 焉 & $\mid \begin{array}{l} \pm \\
\vdots \\
\Xi\end{array}$ & $\mid \begin{array}{c}\infty \\
\vdots \\
\vdots \\
\Xi\end{array}$ & 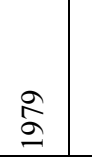 & $\stackrel{g}{ }$ & 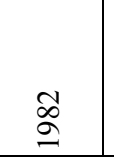 & & 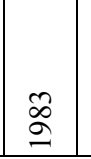 & 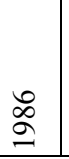 & 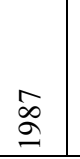 & gొ & g & 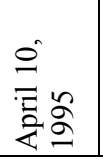 & 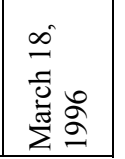 \\
\hline
\end{tabular}




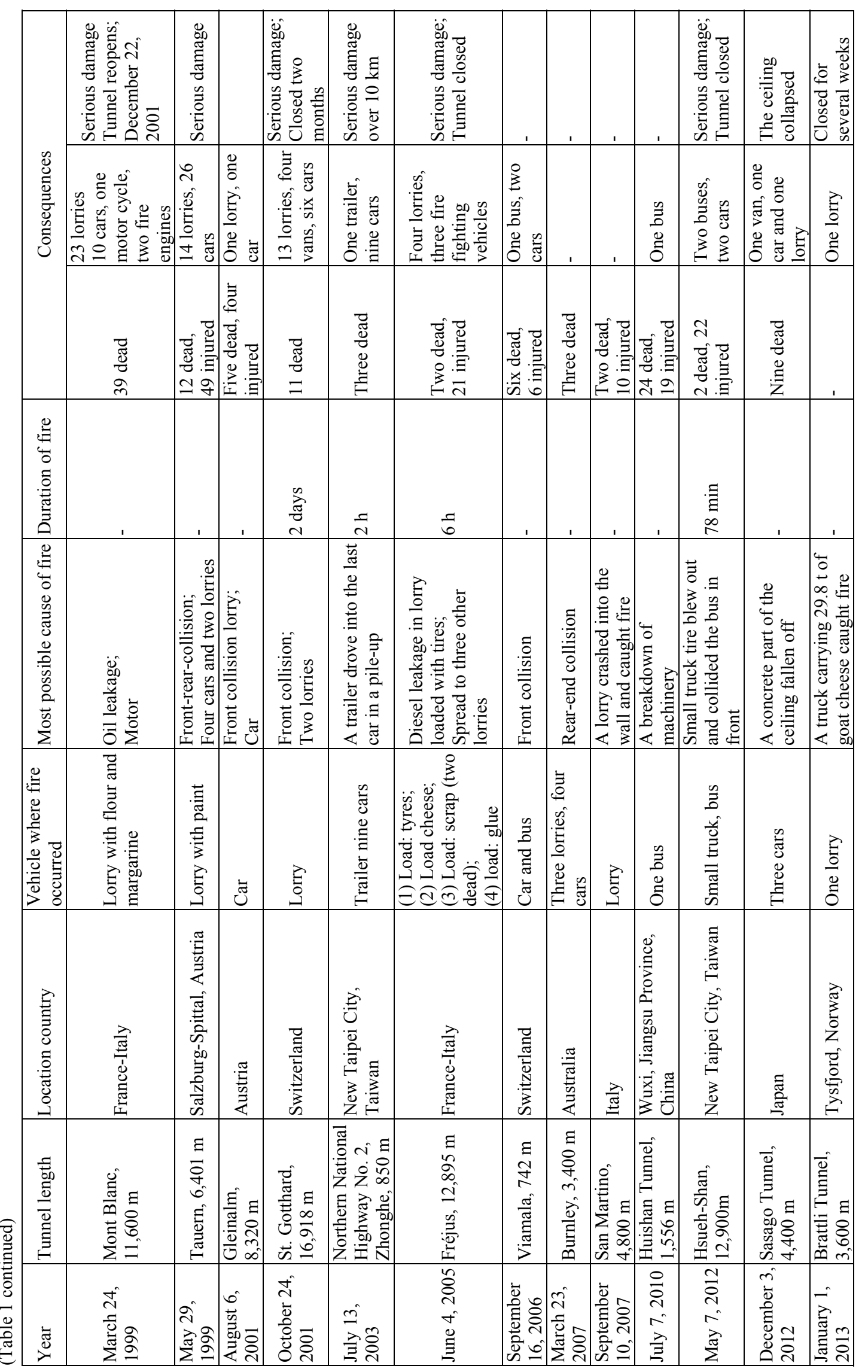




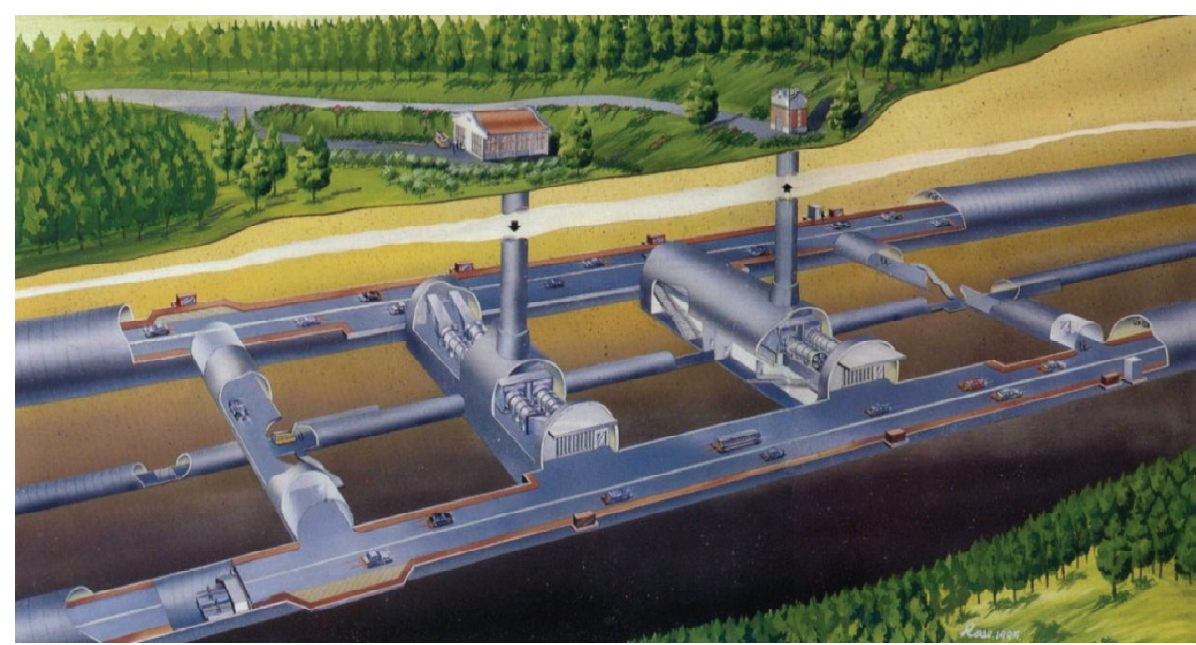

\section{Fig. 1 Perspective of Hsueh-Shan Tunnel.}

function, $s$ is the unit normal direction vector and $k_{n}(x)$ is the absorption coefficient. The bounding condition for the radiation intensity leaving a gray diffuse wall is given as:

$$
I_{w}(s)=\varepsilon I_{b w}+\frac{1-\varepsilon}{\pi} \int_{s^{\prime} \cdot n_{w}<0} I_{w}\left(s^{\prime}\right)\left|s^{\prime} \cdot n_{w}\right| d \Omega
$$

where, $I_{w}$ is the intensity at the wall, $I_{b w}$ is the black body intensity at the wall, and $\varepsilon$ is the emissivity rate.

\subsection{Thermal Boundary Conditions}

The type of thermal boundary conditions applied at any given surface depends on whether that surface is to heat up and burn, whether the burning rate will simply be prescribed, or whether there is to be any burning at all.

\subsubsection{Convective Heat Transfer to Walls}

This condition is used in a solid surface consisting of gains and losses from convection and radiation. In DNS calculation, the convective heat flux to a solid surface $q_{c}^{\prime \prime}$ is obtained directly from the gas temperature gradient at the boundary.

$$
q_{c}^{\prime \prime}=-k \frac{\partial T}{\partial x}
$$

In LES calculation, the convective heat flux to the surface is obtained from a combination of natural and forced convection correlations:

$$
\begin{gathered}
\dot{q}_{c}^{\prime \prime \prime}=h \Delta T \\
h=\max \left[C|\Delta T|^{1 / 3}, 0.037 \frac{K}{L}\left(\frac{|U| L}{V}\right)^{0.8} P_{r}^{1 / 3}\right]
\end{gathered}
$$

\subsubsection{Pyrolysis Model with Thermally-Thick Solid}

If the material is assumed to be thermally-thick, a one-dimensional heat conduction equation is applied. The equation is [19]:

$$
\begin{aligned}
\rho_{S} C_{S} \frac{\partial T_{S}}{\partial t} & =k_{S} \frac{\partial^{2} T}{\partial x^{2}} \\
-k_{s} \frac{\partial T_{s}}{\partial x}(o, t) & =\dot{q}_{c}^{\prime \prime}+\dot{q}_{r}^{\prime \prime}
\end{aligned}
$$

where, $\rho_{S}, C_{S}$ and $k_{S}$ are the (constant) density, specific heat and conductivity of the material, $q_{c}^{\prime \prime}$ and $q_{r}^{\prime \prime}$ are the convective and radiative heat fluxes at the surface. If the material is assumed to ignite and burn at some prescribed temperature $T_{p}$, then Eq. (12) can be described as follows:

$$
T_{S}(0, t)=T_{p} ; q_{p}^{\prime \prime}=q_{c}^{\prime \prime}+q_{r}^{\prime \prime}+k_{S} \frac{\partial T_{S}}{\partial x}(0, t)
$$

where, $q_{p}$ is the energy available for paralyzing fuel, which can be specified and expressed as Eq. (13):

$$
m^{\prime \prime}=\frac{q_{p}^{\prime \prime}}{\Delta H_{v}}
$$

3.3.3 Pyrolysis Model with Thermally-Thin Solid

If the material is assumed to be thermally-thin and the temperature is uniform across width, the governing Eq. (14) is annotated as below: 


$$
\frac{d T_{s}}{d t}=\frac{\dot{q_{c}^{\prime \prime}}+\dot{q_{r}^{\prime \prime}}}{\rho_{s} C_{s} \delta}
$$

where, $\delta$ is thickness. In this case, the individual values of the parameters, and are not as important as their products. The pyrolysis temperature is expressed as Eq. (15):

$$
T_{S}=T_{p} ; q_{p}^{\prime \prime}=q_{c}^{\prime \prime}+q_{r}^{\prime \prime}
$$

\section{Common Ventilation System and Smoke Control Mode in Long Tunnel}

When the fire in Hsueh-Shan Tunnel occurred, the timing of ventilation control and the constant pressure exhaust system are not proper for escape and rescue operation, causing serious causalities, as shown in Fig. 2 [19]. Cross-flow ventilation system involves a relatively larger excavation area and requires higher power and higher construction cost. However, it is suitable in long tunnel as exhaust gas accumulates less. In view of the above-mentioned, the post-disaster recovery of Gotthard Road tunnel and many of the reconstruction or construction of long tunnel ventilation system around the world adopt the central exhaust system [20]. The ventilation and exhaust system can be classified into longitudinal ventilation, transverse ventilation (Fig. 2a), semi-transverse ventilation (Fig. 2b), and longitudinal with point extraction ventilation (Fig. 2c) which are the latest trend [21, 22]. Hsueh-Shan Tunnel is the longitudinal ventilation and exhaust system.

The design standards of tunnel ventilation system used around the world are virtually the same; The majority of them use natural, longitudinal, semi-transverse or transverse ventilation. In short tunnels, piston effect could participate in longitudinal and transverse ventilation. Furthermore, semi-transverse ventilations are needed in the case of long tunnels. For the ventilation system to perform smoke exhaust, the ventilation channel and devices must be thermal-resistant.

Long tunnels in Taiwan, especially those on freeway, are separated twin-bore tunnels. In the case of Hsueh-Shan Tunnel, three sets of ventilation and relay stations are established, with separated shafts for fresh air and exhaust gas to enter and escape. By using exhaust fans for longitudinal ventilation, air quality can

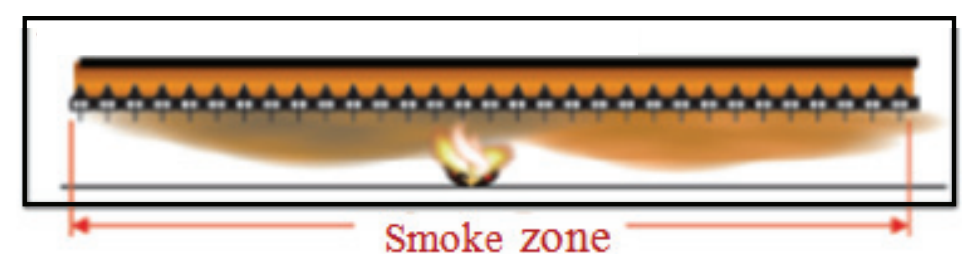

(a)

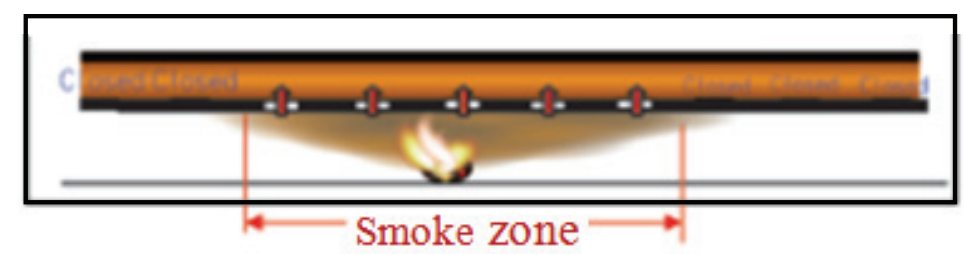

(b)

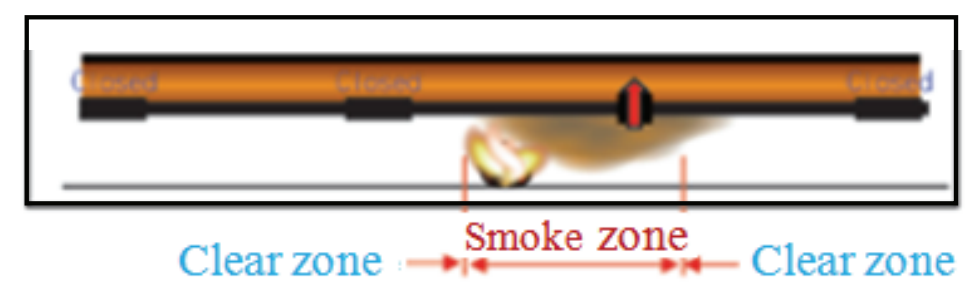

(c)

Fig. 2 Evolution of international road tunnel exhausted system [11]: (a) transverse ventilation; (b) semi-transverse ventilation; (c) longitudinal \& point extraction ventilation. 
be guaranteed with less energy waste. With fire brigades reside at both ends of the tunnel, once fire is detected, the firefighters will be in operation with fire motorbike, guiding the victims to evacuate within the optimum rescue period.

\section{Simulation and Analysis}

This research aimed on investigating better smoke control system for reducing the number of casualties in fire than current configuration. According to "Plan of Road Accidents and Overall Precaution \& Rescue of Hsueh-ShanTunnel" approved by Executive Yuan, Taiwan, R.O.C., 2012, when fire breaks out in a tunnel, in order to provide victims a proper environment to escape, the fans ought to be in operation as preset. Furthermore, this operation can be divided into two steps.

\subsection{Evacuation Mode}

To help victims adequately escape from fire site, the first step is shutting down the fans and closing affiliated air doors to prevent smoke from spreading to neighboring tunnels. Furthermore, the operation of blowers, exhaust fans, and jet fans follows the ventilation program. In one-way traffic, the wind speed at fire scene should be kept at $2.0 \sim 4.0 \mathrm{~m} / \mathrm{s}$ to force the smoke to spread downwind so as to protect the victims upwind. However, the fans from $250.0 \mathrm{~m}$ upwind to $500.0 \mathrm{~m}$ downwind of the fire scene should not be turned on to decrease the disturbance of smoke layer. Meanwhile, all the fire and smoke doors in tunnel cross-passages should be closed.

\subsection{Smoke Exhaust Mode}

When the victims have already escaped through cross-passages, to avoid the equipment damage caused by high temperature, the smoke exhaust mode must be launched by staff in control center. In addition, to assist the firefighters to operate promptly, all the blowers exhaust fans, and jet fans must be activated to make higher wind speed.

However, on May 5, 2012, the fire accident at $26.0 \mathrm{~km}$, southbound in Hsueh-Shan Tunnel caused numerous victims suffered from smoke inhalation injury. Moreover, the cross-passages and shafts were all filled with smoke. Therefore, to find a better way which can alleviate the damage caused to victims, this research is to compare the current 2-step smoke exhaust mode with the others.

This simulation is based on a real case in a tunnel $200.0 \mathrm{~s}$ before the fire accident happened; The blowers were activated to keep the wind at a stable speed of $2.0 \sim 4.0 \mathrm{~m} / \mathrm{s}$. After that, one vehicle was simulated to be on fire at the 201th second. Moreover, the maximum fire load of simulated tunnel was $30.0 \mathrm{MW}$ (Table 2) $[13,23]$ as referred to the structural design of Hsueh-Shan Tunnel. The control center would confirm the fire case within $60.0 \mathrm{~s}$ and launch the smoke exhaust mode at the 260th second. The followings are three different smoke exhaust modes to probe the scenario, as listed in Table 3:

(1) Mode 1: Follow the first step of current ventilation operating mode so that the fans within the fire scene $250.0 \mathrm{~m}$ upwind and $500.0 \mathrm{~m}$ downwind are shut down at the 260th second;

Table 2 Details of relevant simulation parameters.

\begin{tabular}{lll}
\hline Parameters & Detail & \\
\hline Tunnel space & Size (length $\times$ width $\times$ height $)$ & $5,000.0 \mathrm{~m} \times 10.0 \mathrm{~m} \times 7.0 \mathrm{~m}$ \\
\hline \multirow{3}{*}{ Fire source } & Fire load & $30.0 \mathrm{MW}$ \\
& Fuel & Diesel fuel \\
& Area of fire & $2.0 \mathrm{~m} \times 2.5 \mathrm{~m}$ \\
\hline \multirow{2}{*}{ Relevant simulation parameters } & Environmental starting temperature & $25.0^{\circ} \mathrm{C}$ \\
& Simulation time & $800.0 \mathrm{~s}$ \\
\hline
\end{tabular}


Table 3 Threesmoke exhaust operation modes to probe the scenario.

\begin{tabular}{lll}
\hline \multirow{2}{*}{ Mode } & \multicolumn{2}{c}{ Operation mode } \\
\cline { 2 - 3 } & Before 260th second & After 260th second \\
\hline Mode 1 & Turn on one vehicle for each set & Shut down the fans within the fire scene 250.0 m upwind and 500.0 m downwind \\
Mode 2 & Turn on one vehicle for each set & Remains unchanged \\
Mode 3 & Turn on one vehicle for each set & Launch all the two jet fans in each set \\
\hline
\end{tabular}

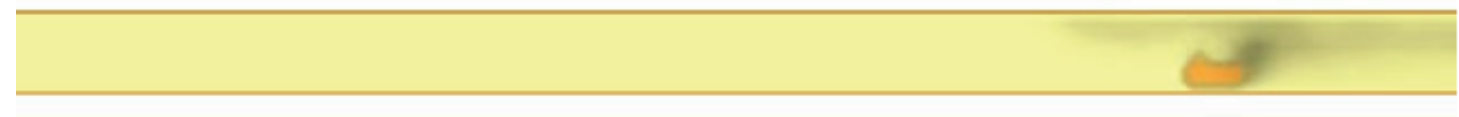

$t=260.0 \mathrm{~s} 60$ th second after fire breaks out

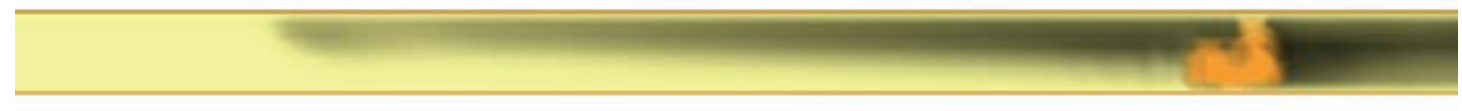

$t=430.0 \mathrm{~s}$ the smokes are $85.0 \mathrm{~m}$ from fire source

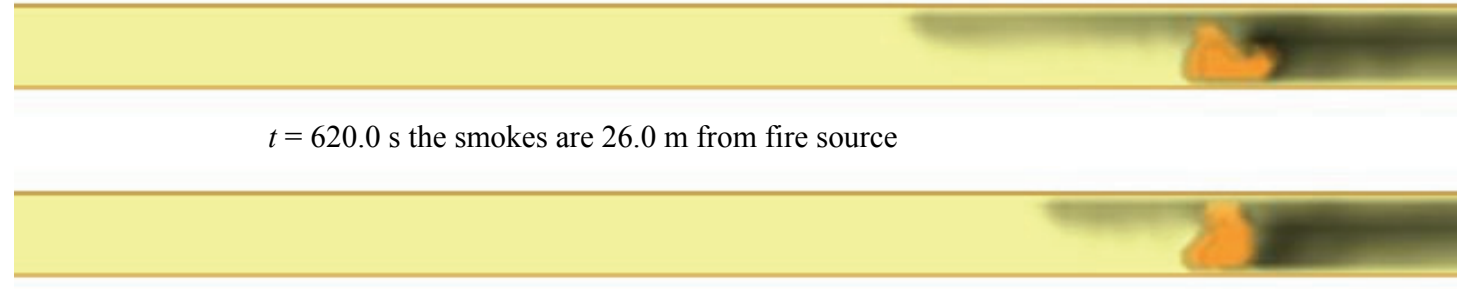

$t=800.0 \mathrm{~s}$ the smokes are $15.0 \mathrm{~m}$ from fire source

Fig. 3 Countercurrent at different timings of Mode 1.

(2) Mode 2: Maintain the ventilation operating mode running, but the fans from $250.0 \mathrm{~m}$ upwind to $500 \mathrm{~m}$ downwind of the fire scene stay on at the 260th second;

(3) Mode 3: Maintain the ventilation operating mode running and launch all the jet fans at the 260th second (there are two jet fans at the same location).

The length of Hsueh-Shan Tunnel is $12.9 \mathrm{~km}$. However, in this case the simulated tunnel is $5.0 \mathrm{~km}$, and the fire load is the same of the construction design of the Hsueh-Shan Tunnel which is $30.0 \mathrm{MW}$. The followings are the analytical results of the three different modes:

(1) In the 430th second of Mode 1, the length of countercurrent is $82.0 \mathrm{~m}$, which is the longest one among the 800.0-s simulation, as shown in Fig. 3. In Mode 2, the longest of the countercurrent is $5.0 \mathrm{~m}$, and the happened time is still around 430th second, as shown in Fig. 4. However, there is no countercurrent happened in Mode 3, mainly because the wind speed is faster than that of countercurrent when all the jet fans are in operation, as shown in Fig. 5 .The distances of the countercurrent of Modes 1-3 are given in Table 4, and the visibility $30.0 \mathrm{~m}$ away from the fire source and the temperature $6 \mathrm{~m}$ above the fire source are presented in Table 5;

(2) In Fig. 6, the visibilities $30.0 \mathrm{~m}$ away from fire source of each mode are below $10.0 \mathrm{~min}$ at the 400th second, which may affect the victims' escape;

(3) In Figs. 7-9, whether the jet fans were switched on affected the upwind temperature profoundly.

The graph of temperature $6 \mathrm{~m}$ above the fire source are disclosed in Fig. 10. In Mode 1, shutting down the fans leads to heat accumulation upon the fire source and causes structural damage. Summarizing the results of Figs. 3-10, in the case of a coach, it would take $2.0 \mathrm{~min}$ for all passengers to get off. Furthermore, conservatively estimating, the walk speed is $0.8 \sim 1.2 \mathrm{~m} / \mathrm{s}$. Therefore, only Modes 2 and 3 can ensure the victims' safety when they escape. 


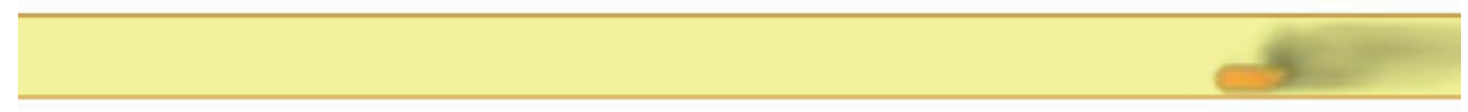

$t=260.0 \mathrm{~s} 60$ th second after fire breaks out

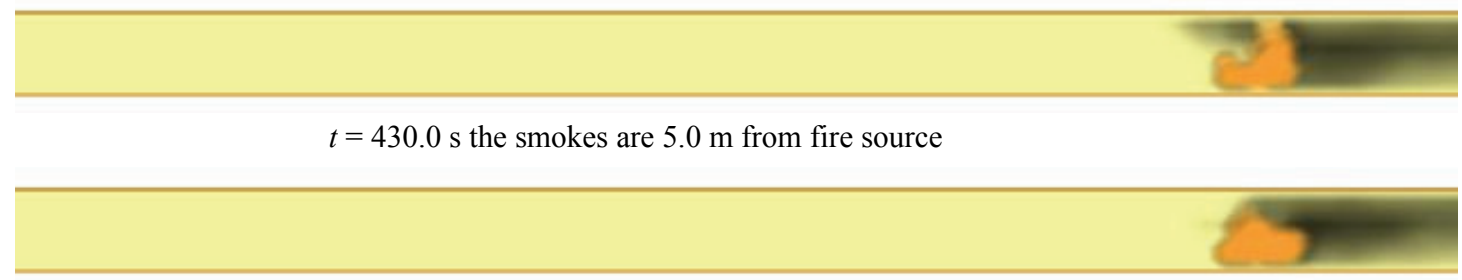

$t=620.0 \mathrm{~s}$ the smokes are $2.0 \mathrm{~m}$ from fire source

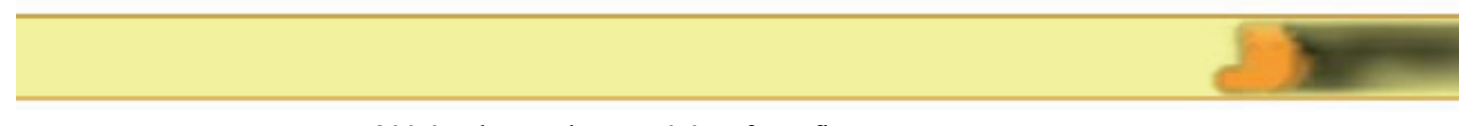

$t=800.0 \mathrm{~s}$ the smokes are $0.0 \mathrm{~m}$ from fire source

Fig. 4 Countercurrent at different timings of Mode 2.

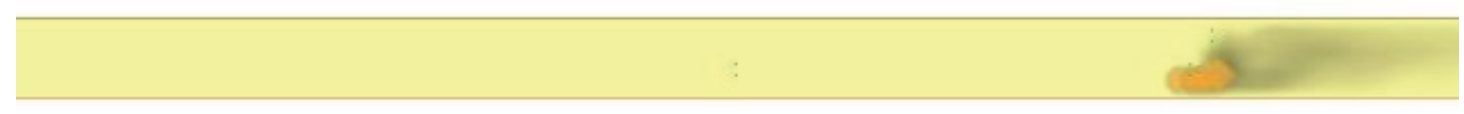

$t=260.0 \mathrm{~s} 60$ th second after fire breaks out

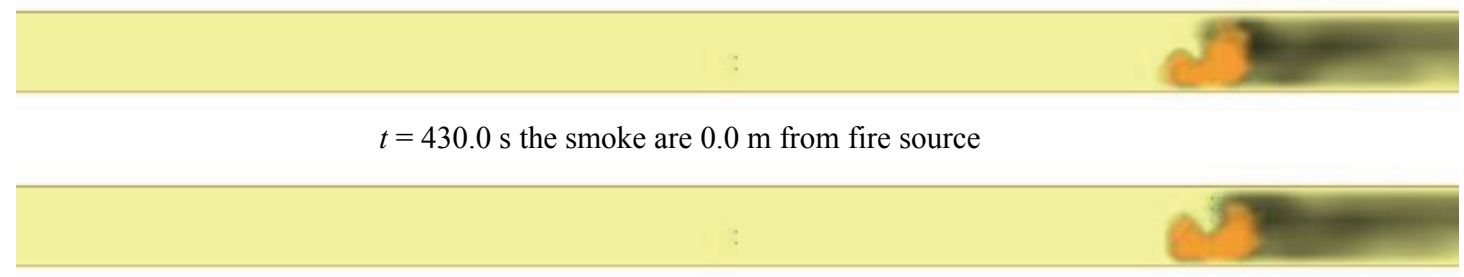

$t=620.0 \mathrm{~s}$ the smoke are $0.0 \mathrm{~m}$ from fire source

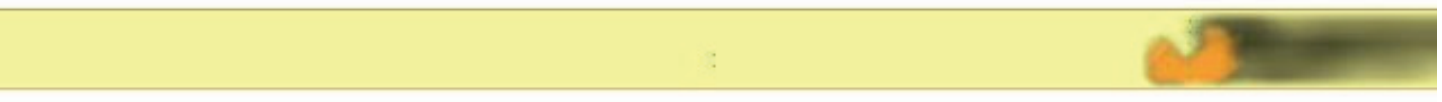

$t=800.0 \mathrm{~s}$ the smoke are $0.0 \mathrm{~m}$ from fire source

Fig. 5 Countercurrent at different timing of Mode 3.

Table 4 Distances of countercurrent at different timing of each mode.

\begin{tabular}{llll}
\hline \multirow{2}{*}{ Mode } & \multicolumn{3}{c}{ Timing } \\
\cline { 2 - 4 } & $430.0 \mathrm{~s}$ & $620.0 \mathrm{~s}$ & $800.0 \mathrm{~s}$ \\
\hline Mode 1 & $82.0 \mathrm{~m}$ & $26.0 \mathrm{~m}$ & $15.0 \mathrm{~m}$ \\
Mode 2 & $5.0 \mathrm{~m}$ & $2.0 \mathrm{~m}$ & $0.0 \mathrm{~m}$ \\
Mode 3 & $0.0 \mathrm{~m}$ & $0.0 \mathrm{~m}$ & $0.0 \mathrm{~m}$ \\
\hline
\end{tabular}

Table 5 Visibility and temperature of three modes.

\begin{tabular}{lll}
\hline Mode & Visibility at $30.0 \mathrm{~m}$ from fire scene $(400.0 \mathrm{~s})$ & Temperature $6.0 \mathrm{~m}$ above the fire source $(420.0 \mathrm{~s})$ \\
\hline Mode 1 & $11.1 \mathrm{~m}$ & $775.0{ }^{\circ} \mathrm{C}$ \\
Mode 2 & $30.0 \mathrm{~m}$ & $568.0{ }^{\circ} \mathrm{C}$ \\
Mode 3 & $30.0 \mathrm{~m}$ & $334.0^{\circ} \mathrm{C}$ \\
\hline
\end{tabular}




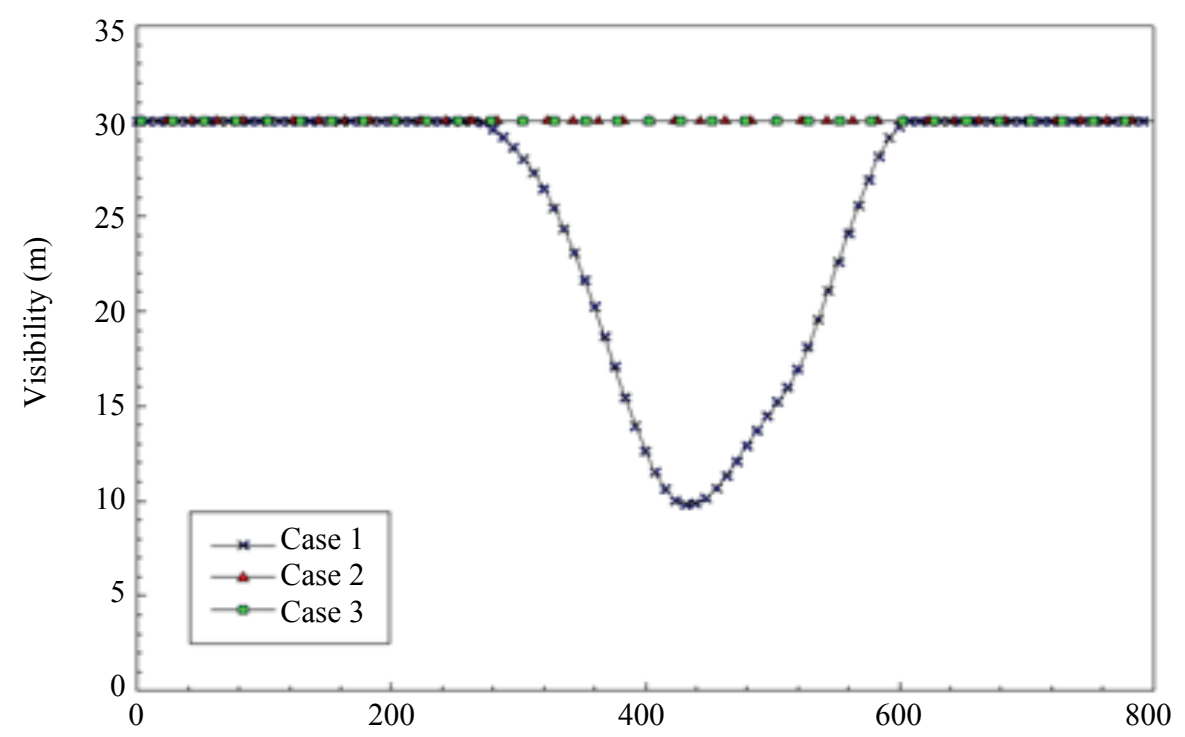

Fig. 6 Visibilities $30.0 \mathrm{~m}$ away from fire source.

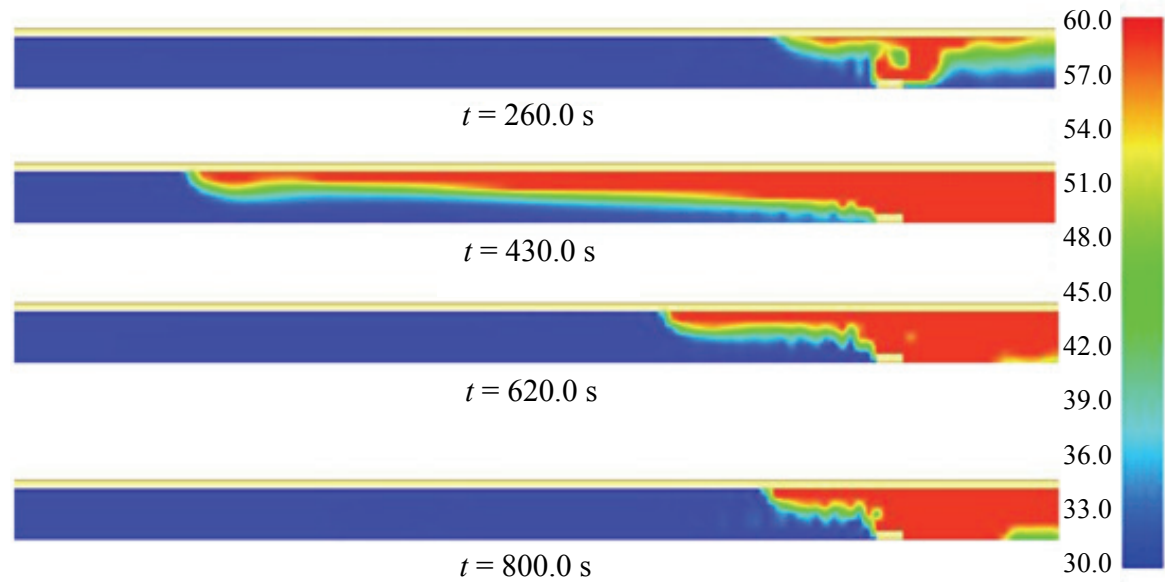

Fig. 7 Sectional view of temperature at different timings of Mode 1.

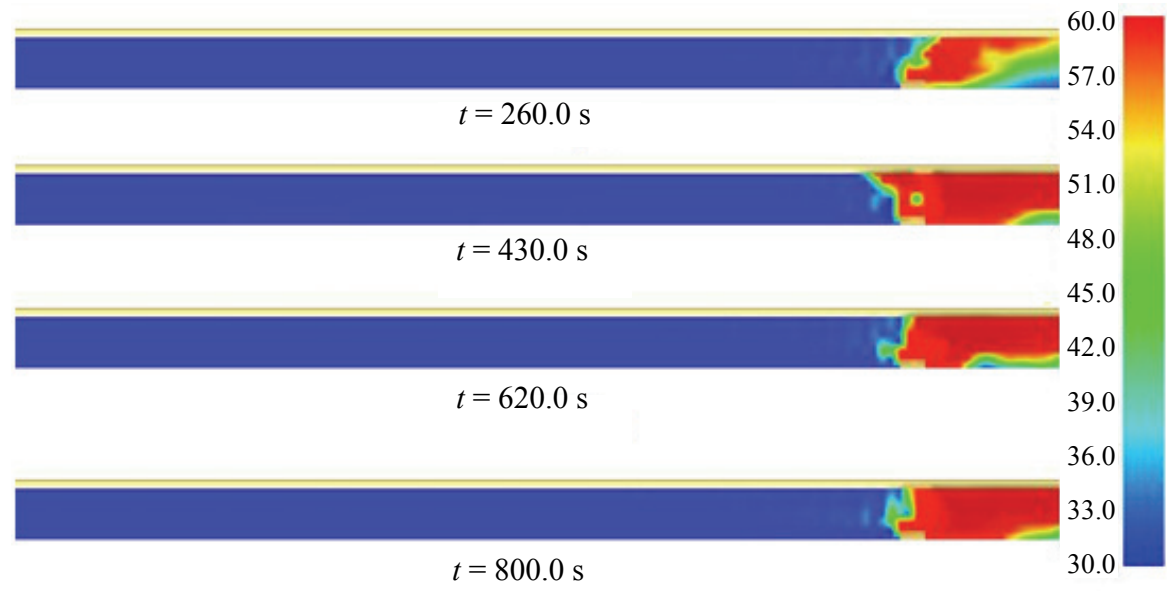

Fig. 8 Sectional view of temperature at different timings of Mode 2. 


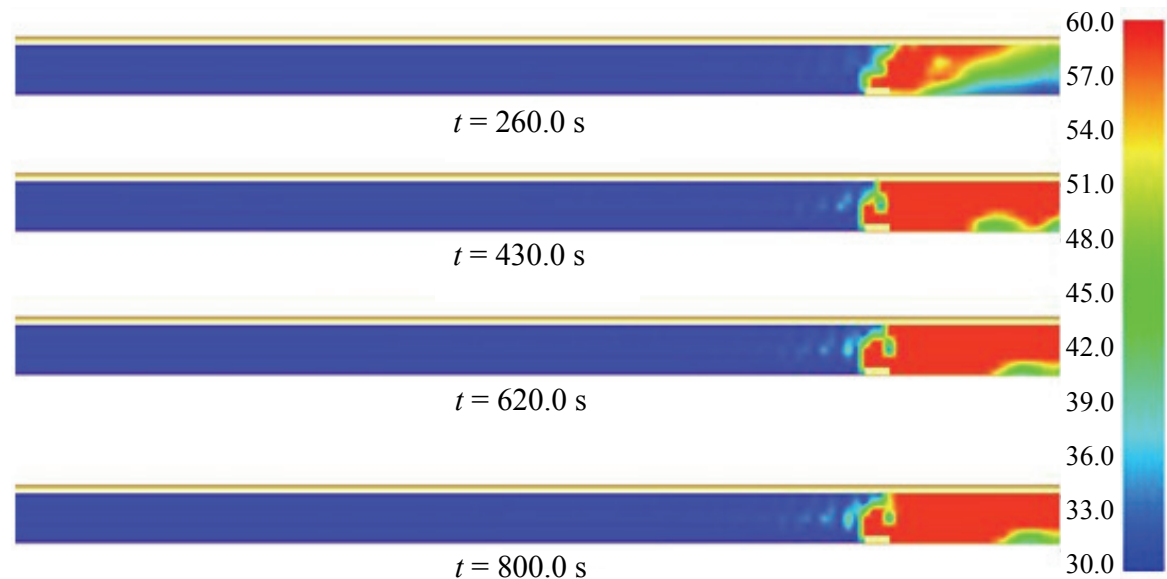

Fig. 9 Sectional view of temperature at different timings of Mode 3.

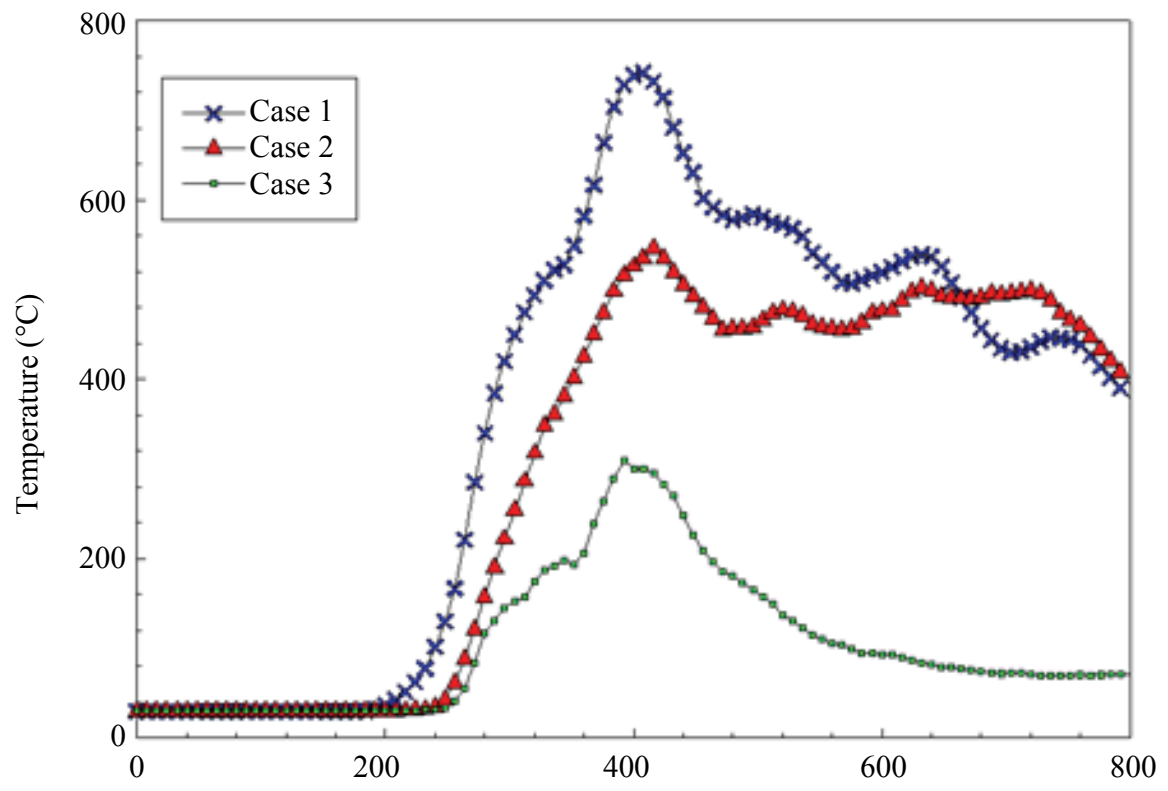

Fig. 10 The change map of temperature $6 \mathrm{~m}$ above the fire source.

\section{Conclusions}

Because the fact that Hsue-Shan Tunnel is the longest tunnel among all of the Taiwan's, it took a long time to construct. Meanwhile, it is also the most important road to communicate the east and west of Taiwan. Therefore, the maintenance and care of the tunnel are vital. However, the traffic accidents are still unavoidable, leading to an important fact that how to keep the safety to the people inside the tunnel when the fire breaks out and how to reduce the damages they might take also the damages to the tunnel. This analysis used FDS to implement the scenario evaluations. The FDS is the fire simulation software to make sure the applicability toward this case. Furthermore, the followings are the results drawn from this study:

(1) In the comparison of Modes 1 and 2, it can be seen that, without shutting down upwind and downwind fans as in Mode 2, the distance of the countercurrent smoke layer is shorter than that in Mode 1. It favors the escape of victims upwind;

(2) In the case of $2.0 \sim 4.0 \mathrm{~m} / \mathrm{s}$ wind speed, the distance of the countercurrent smoke layer is shorter than $50.0 \mathrm{~m}$. To avoid disturbance of smoke layer and 
pursue the safety of upwind victims, it is suggested to shorten the condition of shutting down the fans from within $250.0 \mathrm{~m}$ upwind to within $50.0 \mathrm{~m}$ upwind;

(3) The activation of axial fan can affect the heat accumulation upon the fire source, avoiding partial high temperature which leads to damaging in the interior structure of tunnel;

(4) The escape of victims should be given the highest priority. Thus, the authority is suggested to adopt Mode 3 to ensure safety of upwind victims by avoiding the existence of countercurrent smoke layer.

\section{References}

[1] McGrattan, K., Hostikka, S., McDermott, R., Floyd, J., Weinschenk, C., and Overholt, K. 2013. Fire Dynamics Simulator, Technical Reference Guide. Vol. 1: Mathematical Model. 6th ed. Gaithersburg and Espoo: National Institute of Standards and Technology and VTT Technical Research Centre of Finland, 3-220.

[2] Chung, M. H. 2005. Numerical Simulation of Smoke Control System in Long Tunnels-Study on the Effect of the Number of Exhaust Ports. Taipei: World Long Tunnel, 627-33.

[3] Lee, H. C., and Yang, C. C. 2004. "Scale Model Experiment for the Ventilated Air Interference at Intermittent Tunnels." Presented at International Conference on Tunnel Safety and Ventilation, Graz, Austria.

[4] Hu, L. H., Huo, R., Wang, H. B., and Yang, R. X. 2007. "Experimental and Numerical Studies on Longitudinal Smoke Temperature Distribution Upstream and Downstream from the Fire in a Road Tunnel." J. Fire Sci. 25: 23-43.

[5] Lee, S. R., and Ryou, H. S. 2006. "A Numerical Study on Smoke Movement in Longitudinal Ventilation Tunnel Fires for Different Aspect Ratio." Build Environ. 41: 719-25.

[6] Chiu, H. 2005. "The New Design Concept of Ventilation Systems for Long Road Tunnel in Taiwan.” Presented at International Symposium on Design, Construction and Operation of Long Tunnels, Taipei, Taiwan.

[7] Liu, Y., Apte, V., Luong, Y., Liu, X., Yung, D. 2007. “A Methodology for Assessment of Visibility During Road Tunnel Fires.” J. Fire Prot. Eng. 17: 65-79.

[8] Lotschberg, G. 2003. Tunnel Safety. Niedergesteln: The World's Longest Tunnel.

[9] Lin, C. J., and Chuah, Y. K. 2008. "A Study on Long Tunnel Smoke Extraction Strategies by Numerical Simulation." Tunnelling Underground Space Technol. 23:
522-30.

[10] Kirytopoulos, K., Konstandinidou, M., Nivolianitou, Z., and Kazaras, K. 2014. "Embedding the Human Factor in Road Tunnel Risk Analysis." Process Saf. Environ. Prot. 92: 329-37.

[11] Zhang, L., Wu, X., Ding, L., and Skibniewski, M. J. 2013. "A Novel Model for Risk Assessment of Adjacent Buildings in Tunneling Environments." Build Environ. 65: 185-94.

[12] Zhang, L., Wu, X., Chen, Q., Skibniewski, M. J., and Hsu, S. C. 2014. "Towards a Safety Management Approach for Adjacent Buildings in Tunneling Environments: Case Study in China." Build Environ. 75: 222-35.

[13] U.S. Department of Transportation, FHWA (Federal Highway Administration). 1999. "Fire Accidents in the World's Road Tunnels.” FHWA. Accessed July 26, 2015. http://lotsberg.net/artiklar/brann/en_tab.html.

[14] Taiwan Area National Freeway Bureau, Ministry of Transportation and Communications. 2012. "The Investigation Report of Hsueh-Shan Tunnel Accident, The Control Yuan, R.O.C." Ministry of Transportation and Communications. Accessed November 11, 2012. http://www.tpce.org.tw/tpce/epaper/news/430-1.htm.

[15] Drysdale, D. 2011. An Introduction to Fire Dynamics. 3rd ed. New York: John Wiley and Sons, 36.

[16] Grinstein, F. F., Margolin, L. G., and Rider, W. J. 2007. Implicit Large Eddy Simulation: Computing Turbulent Fluid Dynamics. Cambrige: Cambrige University, 45.

[17] Janna, W. S. 1991. Introduction to Fluid Mechanics. 2nd ed. Boston: Prindle, Weber and Schmidt, 19.

[18] McGrattan, K. B., Hostikka, S., and Floyd, J. E. 2010. Fire Dynamics Simulator (Version 5), Technical Reference Guide, Vol. 1: Mathematical Model. Gaithersburg and Espoo: National Institute of Standards and Technology, U.S. Department of Commerce and VTT Technical Research Centre of Finland, 55-61.

[19] American Society of Civil Engineers. 2001. "Tunnel Fire Investigation II: The St. Gotthard Tunnel Fire.” In The Handbook of Tunnel Fire Safety. Reston: American Society of Civil Engineers.

[20] Li, J. S. M., and Chow, W. K. 2003. "Numerical Studies on Performance Evaluation of Tunnel Ventilation Safety Systems." Tunnelling and Underground Space Technology 18 (5): 435-52.

[21] Ota, Y. 2003. "Study on Smoke Extraction Strategies by Numerical Simulation." Presented at 5th International Conference for Safety in Road and Rail Tunnels (ITC), Marseille, France.

[22] Ota, Y., and Kenji, H. 2001. "An Analysis of Thermal Environment for Road Tunnel in the Incidence of Fire." Presented at 3rd International Conference on Safety in Road and Rail Tunnels (SIRRT), Madrid, Spain. 
Tunnel Accident in Taiwan

[23] Palazzi, E., Curro, F., and Fabiano, B. 2005. "A Study on Road Tunnel Fires Using Hazmat, with Emphasis on
Critical Ventilation Velocity." Process Saf. Environ. Prot. 83: 443-51 